\title{
Normal placental development and the triad of placental dysfunction: The maternal and fetal complications
}

\author{
Normal plasental gelişim ve plasental disfonksiyon triadı: \\ Maternal ve fetal komplikasyonlar
}

\author{
Arielle Hough, ${ }^{1}$ Sathees B. Chandra² \\ Biomedical Sciences Program, College of Nursing and Health Sciences, Barry University, Miami Shores, USA
}

\begin{abstract}
The placenta is crucial to the development of a fetus, playing a vital role from fertilization of an egg by sperm until the delivery of the fetus. Without the placenta, the fetus would not receive essential nutrients or oxygen from the mother and be able to rid itself of toxic wastes. Given the necessity of this temporary organ, improper formation of the placenta can lead to many health problems. These complications have an effect on the mother as well as the fetus given the essential link the placenta makes between fetal and maternal circulation. The main concerns with impaired placental function are commonly known as the triad of placental dysfunction. The triad of placental dysfunction includes preeclampsia, HELLP Syndrome, and (Intrauterine Growth Restriction) IUGR. The purpose of this review article is to explore the pathogenesis, the diagnostic and predictive criteria, and treatment for the disorders composing the triad of placental dysfunction to allow better outcomes for both the mother and fetus.
\end{abstract}

Keywords: Fetus; HELLP syndrome; IUGR (Intrauterine Growth Restriction); placenta; preeclampsia

$T$ he Placenta is a critical part of a healthy pregnancy. The placenta provides the developing fetus with oxygen and nutrients and removes waste products from the blood. The placenta rests on the wall of the uterus and gives rise to the umbilical cord that attaches the fetus to the maternal circulation. This organ is temporary and is delivered with the baby either vaginally or by C-section. ${ }^{[1,2]}$ The placenta is also the source of many hormones essential for a healthy pregnancy. Due to its pivotal role in pregnancy, correct development of the placenta is crucial. Abnormal development of the placenta can lead to a number of health conditions that further compli-

\begin{abstract}
Özet
Amaç: Bir yumurtanın sperm tarafından döllenmesinden, fetüsün doğuşuna kadar önemli bir rol oynayan plasenta, fetüsün gelişimi için çok önemlidir. Plasenta olmadan, fetus anneden gerekli besinleri ya da oksijeni alamaz ve toksik atıklardan kurtulamaz. Bu geçici organın gerekliliği göz önüne alındığında, plasentanın yanlış oluşması birçok sağlık sorununa neden olabilir. Fetal ve maternal dolaşım arasında yaptığı temel bağlantı nedeniyle plasentada oluşacak bu komplikasyonların fetusun yanı sıra anne üzerinde de etkisi vardır. Bozulmuş plasental fonksiyon ile ilgili ana endişeler, yaygın olarak, plasental disfonksiyonun üçlüsü olarak bilinir. Plasental disfonksiyon üçlüsünde preeklampsi, HELLP Sendromu ve IUBG (Intrauterin Büyüme Geriliği) bulunur. Bu derlemenin amacı hem anne hem de fetüs için daha iyi sonuçlara erişmek amacıyla plasental disfonksiyon üçlüsünü oluşturan hastalıkların patogenezini, tanı ve öngörü kriterlerini ve tedavisini araştırmaktır.
\end{abstract}

Anahtar Sözcükler: Fetus; HELLP sendromu; IUGR (Intrauterin Büyüme Geriliği); plasenta; preeklampsi

cate a pregnancy that could otherwise be potentially normal or healthy. These conditions include those that involve abnormal conditions of the placenta in the uterus: placenta abruption, placenta Previa, and placenta accrete. Then, there are the more serious of the placental conditions that include preeclampsia, HELLP Syndrome, and Intrauterine Growth Restriction (IUGR). These three disorders are commonly referred to as the Triad of Placental Dysfunction. ${ }^{[2-4]}$

Preeclampsia is defined as a multisystem disorder that affects almost $3 \%$ to $5 \%$ of all pregnancies worldwide and results in an estimated 60,000 maternal deaths annually. ${ }^{[3-5]}$ The disor-

Corresponding (illetişim): Sathees B. Chandra, Biomedical Sciences Program, College of Nursing and Health Sciences, Barry University,

11300 NE Second Ave, Miami, FL 33161, USA

E-mail (E-posta): schandra@barry.edu

Received (Geliş Tarihi): 28.01.2019 Accepted (Kabul Tarihi): 03.05.2019 
der is characterized by a rise in blood pressure with concurrent proteinuria, with both of these occurring after 20 weeks' gestation. Preeclampsia is thought to be the result of abnormal formation of the placenta due to a combination of factors. ${ }^{[1,2,5]}$ The dysfunction can only be cured by delivery; the abnormal placenta is delivered with the baby and blood flow can begin to return to normal. However, even after a safe delivery, mothers are still at risk of developing complications and should be monitored closely. Severe manifestations of pre-eclampsia are described as a sustained blood pressure above $160 \mathrm{mmHg}$ systolic and $110 \mathrm{mmHg}$ diastolic, which can lead to other complications of pregnancy. ${ }^{[6,7]}$ One of these complications is classified as HELLP syndrome. The complication is characterized by hemolysis, elevation of liver enzymes, and a low platelet count. The severity of the complication is shown by the name and it requires an immediate need for emergency care. HELLP syndrome only affects less than $1 \%$ of pregnancies worldwide, but almost 24 percent of those cases results in death. HELLP syndrome is most commonly diagnosed antepartum but can also be diagnosed post-partum within 24 to 72 hours after delivery. Immediate treatment, monitoring in an Intensive Care unit, and surgery in some case is recommended. ${ }^{[8]}$

Lastly, IUGR is the inability of the fetus to thrive while in the mother's uterus, this is said to have occurred in babies in less than the tenth percentile of height, weight, sex, and gestational age. The low birth weight can pose further complications for the baby both while in the uterus, during delivery, and after birth. Just as the mother should be monitored for Preeclampsia and possible development of HELLP syndrome, a baby should be monitored to see if there is a possibility of developing IUGR. ${ }^{[6-8]}$ Early detection of the triad of placental dysfunction is key to treatment and positive outcomes. The management of these complications begins with an understanding of how the placenta should develop under normal or ideal circumstances. The purpose of this review article is to explore the pathogenesis, the diagnostic and predictive criteria, and treatment for the disorders composing the triad of placental dysfunction to allow better outcomes for both the mother and fetus.

\section{Normal development of the placenta}

Once an egg is fertilized it becomes a blastocyst and embeds in the wall of the uterus, at this point development of both the fetus and the placenta begin. Major development of the placenta occurs until thirteen weeks gestation..$^{[1]}$ The placenta begins as a low oxygen area, but as development occurs it becomes a high oxygen area given its function to perform the actions of all fetal organ systems until delivery. ${ }^{[8]}$ The main function of the placenta is to deliver both oxygen and nutrients to the fetus and remove harmful wastes from the fetus. At implantation, a blastocyst forms the trophectoderm that allows implantation into the endometrium, and the chorioallantoic placenta develops. ${ }^{[9]}$ The chorioallantoic placenta is composed of intermediate and smaller sized villi, these villi will eventually become engulfed in maternal blood by remodeling done by the spiral arterioles. ${ }^{[10]}$ The main cell necessary for the remodeling of spiral arterioles is the progenitor cytotrophoblast cell, also known as the stem cell of the placenta. These cells can further differentiate into either a villous cytotrophoblast or an extravillous cytotrophoblast. The villous cytotrophoblast further differentiates into the synctiotrophoblast that performs many essential functions of the placenta. These cells line the exterior villi of the placenta and their specialized epithelium allows for nutrients, and peptide products to be transported from mother to fetus. The transport of these items is necessary for proper functioning of both fetal and maternal processes. ${ }^{[2]}$

The placental villi are lined with extravillous cytotrophoblasts and synctiotrophoblast cells, and as development continues, these villi become increasingly more branched. The Uterine wall is normally lined with blood vessels known as spiral arteries that have to be remodeled to support the placenta. The extravillous cytotrophoblast cells of the placenta penetrate the wall of the uterus and replace the cells of the spiral arteries. ${ }^{[2]}$ This process allows the spiral arteries to become larger than normal to support the necessity for increased blood flow to supply the fetus. In order for a normal pregnancy devoid of placental complications to occur, the cytotrophoblasts must completely remodel the spiral arterioles. Complete remodeling of the spiral arterioles allows for sufficient blood flow and therefore oxygenation. ${ }^{[1,10]}$ When any or all of these mechanisms goes wrong, complications can and will occur during pregnancy that can affect both the mother and the fetus. Severe complications include preeclampsia, HELLP Syndrome and Intrauterine Growth Restriction (IUGR), these are sometimes referred to as the triad of placental dysfunction. ${ }^{[11]}$ The first sign of abnormal development of the placenta is the onset of preeclampsia, the mechanism of placental development that goes wrong in preeclampsia is explained below. Detection of this dysfunction involves being aware of the diagnostic criteria for preeclampsia. ${ }^{[6]}$

\section{Pathogenesis and diagnostic criteria for the detection of preeclampsia}

Pre-eclampsia is thought to develop due to abnormalities in the placenta, this is credited to the fact that the only known cure for preeclampsia is delivery and removal of the placenta. Onset is thought to be the result of dysfunction of the endothelium and the extravillous cytotrophoblasts. The cytotrophoblasts fail to completely remodel the spiral arteries. ${ }^{[12]}$ Cytotrophoblasts are responsible for the switching of the integrin surface proteins that give the arterioles an endothelial phenotype. This switching of cell surface markers on integrin's is a process known as pseudovasculogenesis. In preeclampsia, the cells fail to complete the change. ${ }^{[10]}$ This abnormal development leads to placental ischemia and further releases substance into the mother's blood stream that cause the clinical symptoms present in mothers with preeclampsia. The endothelial derived vasoactive factors are unbalanced and vasoconstrictive substances such as endothelin and thromboxane $\mathrm{A} 2$ predominate in the vasculature. Excess 
vasoconstrictive factors decrease the diameter of major arteries and explain the increase in blood pressure. ${ }^{[13]}$ Despite the increase in blood pressure, the placenta does not receive enough blood and must compensate. Therefore, Microcirculation takes over in a process known as angiogenesis and vast networks of small vessels form. However, this process is not sufficient to provide optimal oxygenation. ${ }^{[14]}$ The placenta is mainly responsible for preeclampsia development but other environmental factors can also come into play, more research is necessary to determine how these immunologic, genetic, and environmental factors come into play. ${ }^{[2,3]}$ Given the complex nature of preeclampsia, management of the disease is crucial to prevent adverse neonatal outcomes, including IUGR.

Preeclampsia is suspected during pregnancy when a mother presents with elevated blood pressure. High blood pressure occurring in pregnancy can be divided into 5 groups: preeclampsia, gestational hypertension, concurrent preeclampsia and preexisting hypertension, chronic hypertension and postpartum hypertension. Of these groups, Preeclampsia is a systemic disorder that occurs after 20 weeks of gestation and is marked by a sudden elevation in blood pressure. The sudden elevation in blood pressure is accompanied by proteinuria (protein in the urine). ${ }^{[15]}$ The continuum of preeclampsia ranges from mild to severe. ${ }^{[16]}$ The designation of disease severity is critical to the treatment plan, but the severity classification is commonly debated due to the disagreement on the pathophysiology. ${ }^{[17]}$

Severe Pre-eclampsia starts with a systolic blood pressure reading above $160 \mathrm{mmHg}$ and a diastolic reading above 110 $\mathrm{mmHg}$ for two readings taken 6 hours apart. Mild manifestations of preeclampsia, on the other hand, is classified by a systolic reading above $140 \mathrm{mmHg}$ and a diastolic above 90 $\mathrm{mmHg}$, the same criteria applies for the sustained nature of the hypertension, two readings 6 hours apart. ${ }^{[16,17]}$ The protein excretion in the urine decreased to $300 \mathrm{mg}$ in a 24-hour collection period for mild cases. However, preeclampsia has a sudden onset sometimes in women with no history of elevated blood pressure or excess protein excretion in the urine. Another criterion used in the diagnosis of pre-eclampsia versus regular high blood pressure is the presence of other concurrent symptoms and signs of organ damage. ${ }^{[18]}$ These symptoms include neurologic disturbances (including headaches, vision loss, seizures), pulmonary edema, renal compromise, hepatic dysfunction, thrombocytopenia, placental abruption, and oligohydramnios. ${ }^{[19]}$ The diagnostic criteria should be used in conjunction with biochemical markers that are related to preeclampsia and the placental dysfunction.

\section{Biochemical prediction markers for early detection of preeclampsia}

The key to correctly managing and preventing adverse maternal and fetal outcomes is prediction and early detection of preeclampsia. Over the years, scientists have come up with different angiogenic factors and proteins that play a role in the pathologic process occurring in preeclampsia. First, Vascular
Endothelial Growth Factor (VEGF), was found to be associated with preeclampsia and most importantly endothelial dysfunction. ${ }^{[20]}$ This correlation was made when it was discovered that cancer patients who were treated with the antagonist of VEGF exhibited the same symptoms as those with pre-eclampsia. Therefore, changes in VEGF signaling in endothelial cells can contribute to the manifestation of preeclampsia. ${ }^{[21]}$

In addition, Placental Growth factor-1 is necessary for angiogenesis of the placenta and embryogenesis of the fetus. PGF-1 is said to be secreted from trophoblast cells which are a key factor in placental development. ${ }^{[2]]}$ Soluble fms-like tyrosine kinase 1 (SFLT-1) is found in the blood of mothers with preeclampsia in higher than normal amounts. This protein is secreted from the placenta into the blood stream. SFLT-1 is circulated in the blood and binds to the VEGF and PGF-1 protein receptors. When bound to SFLT- 1 these proteins lose their function and the endothelium of the placenta is no longer able to maintain its anticoagulant and vasodilatory properties. ${ }^{[22]}$ An ELISA test can be performed in mothers exhibiting no symptoms and those exhibiting early signs of pre-eclampsia to determine the SFLT-1/PGF ratio. In a normal pregnancy this ratio is low, while in a pregnancy with preeclampsia the ratio is high. The higher the ratio the more severe the symptoms of pre-eclampsia. The imbalance in the ratio can occur 5 to 6 weeks before a mother will present with symptoms. This assay proves to be helpful in the early stages of the second trimester. ${ }^{[23]}$ Consequently, even mothers who will never develop preeclampsia in pregnancy may have high levels of SFLT-1 compared to PGF-1 and VEGF. Therefore, a higher ratio is not a definite diagnosis but an indicator of preeclampsia. This indicator will allow for stricter monitoring and a more accurate diagnosis of symptoms if they present. Early diagnosis is key in managing this disease. ${ }^{[20]}$

The SFLT-1 and PGF ratio described has proven to be unhelpful in determining the risk of preeclampsia in the first trimester. Doctors have instead used the levels of PGF-1. Low levels of PGF-1 and a uterine artery Doppler can be performed to help predict preeclampsia as early as the first trimester. ${ }^{[23]}$ The uterine artery Doppler can measure the placental blood flow and determine if the flow is insufficient, a condition present in preeclampsia and known as placental ischemia. These techniques can improve the outcomes of a patient with preeclampsia and effect how the patient's pregnancy is managed by obstetricians. These biochemical markers can help in the early diagnosis of preeclampsia to help obstetricians better manage preeclampsia and monitor the fetus more closely as well as the prevention of preeclampsia using medication such as acetylsalicylic acid (ASA). ${ }^{[20]}$

\section{Management and neonatal outcomes of preeclampsia}

The only curative measure in cases of preeclampsia is delivery, removing the placenta will in most cases cure the high blood pressure. ${ }^{[24]}$ The options depend on the severity and the week of gestation when the preeclampsia is diagnosed. Severe preeclampsia occurring in 36 to 37 weeks of gestation is managed 
by inducing labor. From 24 to 34 weeks of gestation, the management will depend on the severity of the symptoms. Immediate delivery is needed after corticosteroid therapy to mature the fetal lungs if a number of other symptoms of comorbidity are present. These symptoms include eclampsia (seizures), acute pulmonary edema, subcapsular hepatic hematoma, and thrombocytopenia. ${ }^{[25]}$ The common corticosteroid treatment is injection of $12 \mathrm{mg}$ of betamethasone 24 hours apart. In all cases of severe preeclampsia, medications must be used to reduce the blood pressure. A severe reduction in blood pressure can help the mother, but it could also harm the fetus if the blood pressure is reduced suddenly. If administration of drugs is determined to provide more benefit than harm, the drugs used in the management of blood pressure are labetalol, dihydralazine, clonidine, and nicardipine. Once delivered, the mother should still be monitored for continued high blood pressure and nervous system disturbances. Laboratory test should also be performed for 72 hours following delivery to rule out other related comorbidities. ${ }^{[26]}$

Preeclampsia has significant effects on the fetus, these affects are due to the abnormal placentation described in the pathophysiology of the disorder. The placenta is the main source of blood flow and nutrients between the mother and the fetus. The different adverse effects on the fetus most commonly include IUGR, Oligohydramnios, and Placental abruption. ${ }^{[27]}$ IUGR, is insufficient fetal growth, and inability to reach a predetermined standard while in the mother's uterus. As noted in preeclampsia, the main cause of IUGR is due to the impaired remodeling of the spiral arterioles, this will lead to hypoxia in the fetus. IUGR which will be discussed further, is part of the triad of placental dysfunction and is a leading factor in cases of perinatal mortality and morbidity. ${ }^{[28]}$ The next fetal affect is oligohydramnios or the lack of amniotic fluid found in the amniotic cavity, this poor development of amniotic fluid is also linked to the abnormal placentation found in preeclampsia. The placenta is insufficient to maintain the amniotic fluid and will cause cord compression, and even fetal death. ${ }^{[29]}$ The last, and one of the more severe of the effects of preeclampsia on the fetus is placental abruption, placenta abruption is when the placenta separates from the uterine wall before delivery. The mother will exhibit symptoms of vaginal bleeding, lower abdominal pain and drop in blood pressure. ${ }^{[30]}$ Preterm abruption of the placenta is more common in preeclampsia and full-term abruption of the placenta is more common in pregnancies complicated by smoking, gestational diabetes, and obesity. Placental abruption causes the need for immediate delivery, resulting in most cases in a preterm birth. ${ }^{[2]}$ Patients with preeclampsia are at risk for developing the complication HELLP syndrome, patients should have bloodwork to rule out HELLP syndrome and be mindful of the symptoms associated.

\section{Diagnostic criteria used for the determination of HELLP syndrome}

HELLP Syndrome, is observed in an estimated 10 to $20 \%$ of severe preeclamptic mothers. ${ }^{[31]}$ The disorder can develop an- tepartum or post-partum, $70 \%$ of these cases are diagnosed before delivery in the $27^{\text {th }}$ to the $37^{\text {th }}$ week of gestation. Postpartum cases make up the remainder and are diagnosed within 48 hours after delivery. A patient presents upon physical examination with right upper quadrant abdominal pain, generalized edema, and significant weight gain. Diagnosis in the early stages is done using laboratory tests to identify, hemolysis, altered liver function, and renal dysfunction. ${ }^{[32]}$ According to the Tennessee Classification system, all three elements must be present. ${ }^{[33]}$ The first element, hemolysis, diagnosed by a LDH (Lactate dehydrogenase) levels above $600 \mathrm{UI} / \mathrm{L}$, accompanied by a decrease in haptoglobin levels. Second, is elevated liver enzymes, given by the enzymes aspartate aminotransferase (AST) and alanine aminotransferase (ALT). ALT and AST levels must be found to be greater than 70 $\mathrm{UI} / \mathrm{L}$. The last element is the low platelet count. The platelet count is found to be less then $100,000 / \mathrm{mm}^{3} .^{[34]}$

Imaging is also required due to the possibility of subcapsular or intraparenchymal hemorrhage and hepatic rupture. The diagnostic markers for HELLP syndrome should be evaluated carefully because they can sometimes mimic those of other liver related disorders in pregnancy. ${ }^{[35]}$ One such disorder is Acute fatty liver of pregnancy (AFLP); a liver biopsy may be done to determine the difference between the two but is not necessary. ${ }^{[19]}$ Liver biopsy of a patient with HELLP syndrome will show focal parenchymatous necrosis, periportal hemorrhage, and macrovascular steatosis..$^{[36]}$ If the patient presented with AFLP as opposed to HELLP syndrome, the liver biopsy would show fatty infiltration of the liver, and diffuse/ perivenular microvascular steatosis. Although liver biopsy is considered the gold standard for diagnosing the difference between these two common disorders of pregnancy. However, there is a risk of hemorrhage associated with the biopsy and it is therefore not feasible. ${ }^{[37]}$ An easier way to differentiate and confirm a diagnosis of HELLP syndrome involves the absence of hypoglycemia, encephalopathy, and prolonged prothrombin time, these are symptoms commonly seen in AFLP. Conversely, HELLP syndrome is characterized by the presence of severe renal dysfunction and hypertension. Both of these disorders require immediate delivery, so an accurate diagnosis is not top priority. ${ }^{[33]}$ These symptoms are best understood in conjunction with the understanding of the pathophysiology of HELLP Syndrome.

\section{The pathologic process in HELLP syndrome}

The pathologic process that occurs in HELLP syndrome is not concrete and necessitates further research. However, it is believed that the syndrome results from abnormal development of the placenta and certain immune mechanisms. The mother develops an immune intolerance to the fetus. Immune complexes, and the anaphylatoxins C3A, C5A, and C5B-9 complement complexes. ${ }^{[35]}$ Vascular active compounds are synthesized from platelets when activated by macrophages and white blood cells. The vascular active compounds cause vasoconstriction explaining the increase in blood pressure and 
concurrent platelet aggregation and consumption. The Renin Angiotensin (RAS) system also plays a vital part in maintaining blood pressure and in HELLP syndrome. Normal RAS involves juxtaglomerular cells of the kidney that convert pro-renin into renin. ${ }^{[36]}$ Renin then converts angiotensin that is released by the liver into angiotensin 1. The ACE enzyme found on the surface of vascular endothelial cells converts angiotensin 1 to angiotensin 2 . Angiotensin 2 promotes intense vasoconstriction and subsequent release of aldosterone that stimulates the absorption of sodium and water into the blood stream. HELLP syndrome is thought to be related to an increase in the amount of Angiotensin 2 produced. In the cases of HELLP syndrome, angiotensin 1 receptors are stimulated by an agonist like effect, further increasing the amount of angiotensin 2 in the blood stream. However, the exact mechanism requires further research. ${ }^{[38]}$

As in the cases of preeclampsia, patients show elevated levels of SFLT-1, but this value alone is not sufficient to explain different comorbidities associated with pre-eclampsia. sENG is the casual factor that seems to be associated with HELLP syndrome and its associated symptoms. endoglin is an angiogenic factor that regulates vascular tone, angiogenesis, and coagulation. sENG, an anti-angiogenic factor, is similar in form to endoglin and thus prevents endoglin from interacting with the appropriate receptor needed to function. ${ }^{[35]}$ The expression of $s E N G$ is upregulated in patients with HELLP syndrome and it inhibits endothelial capillary formation. The inability of the endothelial capillary formation to occur results in decreased placental function. Other angiogenic factors, such as miRNA have proven to be crucial to the development of angiogenic factors and deficient in HELLP syndrome, but the regulation of these factors is unclear. ${ }^{[36]}$ Given the complex pathophysiology and the little understanding we have, further research is necessitated, just as further research is needed for the treatment of HELLP syndrome. The main treatment used today is the administration of high-dose corticosteroids.

\section{Corticosteroid therapy as treatment for HELLP syndrome}

Antepartum cases of HELLP syndrome require immediate delivery in most cases. However, in patients with a fetus with less than 34 weeks gestation, corticosteroid therapy has been used and has shown to be effective. High doses of Corticosteroids have been shown to remedy the critical laboratory values associated with HELLP syndrome. ${ }^{[38]}$ AST, ALT and LDH levels were shown to be significantly affected. Also noted in the study, was an inverse relationship between LDH levels and base platelet count. The lower the platelet count before treatment, the more drastic the change in $\mathrm{LDH}$ levels that were observed. The ability of the corticosteroids to return the critical levels to more normal values can prolong the gestation. In most cases delivery can be pushed off for 48 hours and sometimes longer in the less severe cases. ${ }^{[39]}$ The severity of HELLP syndrome is associated with the platelet count and the LDH levels, therefore these levels are highly indicative of the effec- tiveness of the corticosteroid treatment. ${ }^{[40]}$

In preeclampsia, before the disorder leads to HELLP syndrome, the disease begins with dysfunction of the vascular endothelium. When administered, Corticosteroids function to stabilize the vascular endothelium. The stabilization of vascular endothelium helps to prevent hemolysis of erythrocytes and destruction of platelets. Corticosteroid treatment reduces the necessity for cesarean delivery, blood transfusion, and concomitant infections. ${ }^{[39]}$ However, the study noted no difference in the overall morbidity and mortality of patients treated with corticosteroids in comparison to those who did not receive the treatment. The morbidities noted in both groups, despite the treatment, were placental abruption, adult respiratory distress syndrome, hypoxic ischemic encephalopathy, and retinal detachment. ${ }^{[38]}$ While corticosteroid therapy treatment has shown to improve some outcomes of HELLP syndrome, the key component in reducing maternal morbidity and mortality does not lie in the treatment but ultimately in the early detection of the syndrome. ${ }^{[40]}$ The complications and comorbidities of HELLP syndrome that occur after the onset of symptoms will also require evaluation and treatment.

\section{Evaluation and management of complications associated with HELLP syndrome}

In cases of HELLP syndrome, the most severe part is the aftermath and the complications that come along with the common symptoms as described above. Therefore, these symptoms pose a serious threat to maternal health. These complications can occur soon after diagnosis of HELLP syndrome, but they are sometimes over looked given the beginning of the disease starts with nonspecific symptoms. These symptoms include, headache, nausea, vomiting, flu-like symptoms, malaise, and epigastric pain. The gravest of these complications and therefore the most important is hepatic rupture and hematoma. A Hematoma develops with the collection of blood outside the vessels, thought to be part of the vascular endothelial injury present in the pathogenesis of HELLP syndrome. The patient can be monitored with CT, MRI, and ultrasound and blood transfusions can be administered. The coagulopathy must also be corrected, but the patient is still at risk of liver rupture and in some cases a liver transplant is necessary. Due to the hemodynamic instability caused by HELLP syndrome, patients can go into respiratory failure and the need for ventilation and intubation is imperative. Patients have also presented with Acute Respiratory Distress Syndrome (ARDS), while it only occurs in less than $1 \%$ of patients with HELLP syndrome, intubation is needed as well, but sometimes is not curative. Patients present with laryngeal edema which complicates the intubation process and death can occur. ARDS occurring antepartum in cases of HELLP syndrome results in death in $23 \%$ and $50 \%$ in patients presenting with ARDS after HELLP syndrome postpartum. ${ }^{[41]}$

The main symptoms and diagnosis of HELLP syndrome involves the coagulopathy and the risk for hemorrhage. These severe symptoms can lead to DIC. When a patient enters DIC or dissem- 
inated intravascular coagulation bleeding occurs from many different sites within the body and it is fatal in 38\% of those patients. Management is multidisciplinary and requires hemostatic management, with both a massive blood transfusion and different pharmacological agents. Along with the problems imposed on the liver, HELLP syndrome can cause acute kidney failure in $7.4 \%$ of cases. Patients in kidney failure have an increase vascular permeability and therefore management of fluids is difficult and requires close monitoring. Kidney failure is treated in both antepartum and post-partum cases with dialysis, fluid balance, hemodynamic stabilization, and correction of electrolytes. Lastly, both pre-eclampsia and HELLP syndrome increases the risk of adverse cardiovascular outcomes in the future by 2 to 4 times, this is the same as the increase in cardiovascular risk in patients who smoke. Future complications include chronic hypertension and myocardial infarction. Although the correlation is not concrete, patients should still be monitored closely by a cardiologist. Lifestyle modifications such as diet, aerobic exercise., and subsequent weight loss is also recommended. ${ }^{[41]}$ The severe effects of both preeclampsia and HELLP syndrome also affect the fetus, leading to IUGR.

\section{Predictive markers and diagnosis of IUGR}

IUGR, as stated above, is the failure of the fetus to thrive and develop while in the uterus. ${ }^{[29]}$ This is explained by the fact that IUGR develops when the placenta does not provide sufficient nutrients for the developing fetus. IUGR is linked to the placental insufficiency that occurs when the spiral arteries are not remodeled properly, as described in the development of preeclampsia. This leads to insufficient utero-placental circulation, depriving the fetus of essential nutrients. ${ }^{[42]}$ Studies have been conducted that linked the impaired process of placentation to the concentration of serum placental products found in the blood. These tests need to be used in combination with other biophysical parameters however. The placental volume and function has been shown to be linked to an insulin-like growth factor binding protein, pregnancy associated plasma protein A (PAPP-A), and the levels of beta human chorionic gonadotropin hormone (b-HCG). Low levels of b-HCG and PAPP-A in the $10^{\text {th }}$ to $14^{\text {th }}$ week of gestation has been linked to pregnancy complications including but not limited to IUGR. ${ }^{[43]}$ A-disintegrin and metalloproteinase 12 (ADAM-12) is also an insulin-like growth factor binding protein-protease produced by the placenta, this can be used a s another biomarker when low levels are diagnosed in the first trimester, however, the predictive value is low ranging only from $7 \%$ to $20 \%$. As in the case of pre-eclampsia, an imbalance between the angiogenic and antiangiogenic factors linked to preeclampsia can also be used to indicate possible development of IUGR and the need for close monitoring. ${ }^{[44]}$ Another marker commonly used in the diagnosis of IUGR with a placental pathology is the use of Placental growth factor (PIGF) circulating in the mother's blood stream. The normal values for PIGF ranges from 12-3000 $\mathrm{pg} / \mathrm{ml}$ and depends on gestational age. Using PIGF for indication of IUGR with a placental pathology involves determining a value in less than the $5^{\text {th }}$ percentile, which varies for gestational age. ${ }^{[45]}$

Mitochondrial DNA levels have also been linked to IUGR. Mitochondria provide the fetus and mother with energy in the form of ATP, but in the process, they consume $\mathrm{O}_{2}$. Higher mitochondrial DNA have reported in maternal blood of a fetus with IUGR. This is thought to be due to the fact that the placental $\mathrm{PO}_{2}$ pressure gradient is increased, more $\mathrm{O}_{2}$ will be taken up by the placenta and therefore less oxygen will be delivered to the fetus. ${ }^{[45,46]}$ Another common marker used for the development of IUGR is the use of Doppler ultrasound sampling of Uterine Arteries (UAD). This procedure is non-invasive and focuses on the hemodynamic compartment of fetal and maternal circulation. ${ }^{[46]}$ The UAD can detect when the spiral arteries have failed to remodel completely in the placenta, this is indicated by failure of the vascular compartment to form from high to low resistance. The resistance index (RI) and the pulsality index (PI) in the $90^{\text {th }}$ to $95^{\text {th }}$ percentile is indicative of both future preeclampsia and IUGR. A singe UAD performed with insufficient $R I$ and $P I$ values is not sufficient for a concrete diagnosis, a UAD should be performed between the first and second trimester with sustainably low values during both periods. The UAD results should be combined with other markers for diagnosis. This technique should be especially used in those groups who have been diagnosed with other diseases related to placental dysfunction and are identified as a high-risk group for IUGR. All the parameters described cannot be used as a sole predictor of IUGR. Instead a combination of these parameters should be used. The clinical and biochemical parameters should be combined with the Doppler ultrasound to predict the occurrence of IUGR. The Doppler ultrasound indicates inadequate invasion of the spiral arterioles, while the biochemical values indicate the function of the placenta. IUGR is relatively rare among pregnancies occurring in only about ten percent of pregnancies worldwide, but further research is needed to aid in more predictive early diagnosis of IUGR, given the severe effects on the developing fetus both in the womb and after delivery. ${ }^{[44]}$ It is important to use the markers described above to distinguish whether or not the fetus in fact has placental mediated IUGR or if it is just constitutionally small. This will allow for proper treatment and the avoidance of invasive fetal monitoring or the need for a pre-term delivery. ${ }^{[43]}$ IUGR causes severe effects on the neurological development of the fetus.

\section{Postnatal neurodevelopmental deficits}

Intrauterine Growth Restriction detection is essential to minimize the adverse outcomes present in early childhood in infants with IUGR. More prominent are the neurodevelopmental delays. Survivors of IUGR are at an increased risk for learning impairments, cognitive impairments, motor and sensory deficits, and cerebral palsy. Brain sparing causes the neurodevelopmental deficits to present in infants with IUGR. Brain sparing is when early hypoxia causes vasodilation and increased flow in the anterior cerebral artery. ${ }^{[47]}$ When the hypoxia continues into the third trimester, the middle cerebral 
artery becomes dilated instead and cerebral blood flow increases to favor the deep grey matter of the brain. When brain sparing advances to the middle cerebral artery it is shown to be indicative of more severe neurodevelopmental deficits. The lack of placental blood flow causes chronic hypoxia, and the body adapts to this by redistributing blood flow to the brain as opposed to other fetal body parts. After birth, the infant with brain sparing shows less white brain matter and less content of myelin in the brain. ${ }^{[46,48]}$

Functional deficits occur from infancy to adolescence and young adulthood. A fetal MRI will show less white matter and a delay in myelination of the neurons. The delayed myelination will decrease the speed at which the impulse travels long the neuron. This will manifest in the infant as attention deficits and abnormal behaviors. The MRI also shows a significant decrease in volume in both the cerebellum and the hippocampus. These areas are especially susceptible to the hypoxia imposed on the fetus by the impaired function of the placenta. The hippocampus being responsible for memory and the cerebellum being responsible for coordination and balance will further impair many important functions of the brain. ${ }^{[48]}$ When the IUGR fetus reaches school age, the child will have a lower IQ and will perform below expected levels as compared to the non-IUGR counterparts. The same symptoms of cognition and abnormal behaviors do continue into adulthood, but the adolescent will also show impaired motor ability. The impaired motor ability can be traced back to the lower volume of the cerebellum on a fetal MRI. The abnormal behaviors described will manifest well into adulthood as problems with attention, interaction, anxiety, hyperactivity, irritability, and mood disorders. The amount of brain sparing present does depend on sex, weight at birth, and whether or not the infant was carried to term. Nevertheless, brain sparing poses serious complications for the fetus. ${ }^{[4]}$

\section{Concluding remarks}

Correct formation of the placenta and remodeling of the spiral arteries will allow sufficient blood flow to occur between the mother and the fetus. However, as discussed there are instances when this does not occur and the mother is at risk of developing severe complications. One of these complications is preeclampsia; this hypertensive state of the mother can have many adverse effects on all organs in the body, mainly the liver, kidneys and brain. Preeclampsia extends from just high blood pressure and can lead to different placental mediated complications of pregnancy and pose a risk on the developing fetus. One of the more severe complications for the mother is the development of HELLP syndrome. HELLP syndrome, can and will result in death unless immediate treatment is received. Although development of HELLP syndrome is rare, the complications are severe for both the mother and baby. Further research is needed to determine different environmental and genetic factors of the disease so preventative measures can be taken and at-risk groups identified. The fetus will also suffer the consequences of this dysfunction and can develop IUGR. IUGR is also linked to the placental development; the fe- tus suffers from the lack of available oxygen to the placenta. Our body depends on an adequate supply of oxygen to survive, and the fetus will require just as much oxygen to develop the organs necessary for survival outside the womb. The brain is the organ that pays the major price in the cases of infants with IUGR, manifesting as neurodevelopmental delays. Understanding the complex symptoms and prediction markers available for the diagnosis of the triad of placental dysfunction can help to minimize adverse outcomes leading to the best quality of life for the mother and for the baby. Given the rare occurrence of the triad of placental dysfunction more research is necessary. Further research can better understand preventative measures that can be taken to prevent or predict the abnormal formation of the placenta and to help treat the triad of diseases that can follow placental dysfunction.

Conflict of interest: There are no relevant conflicts of interest to disclose.

\section{References}

1. Cartwright, J. E., \& Whitley, G. S. Strategies for investigating the maternal-fetal interface in the first trimester of pregnancy: What can we learn about pathology? Placenta 2017; 60:145-149.

2. Guttmacher, A., Maddox, Y., \& Spong, C. The Human Placenta Project: Placental structure, development, and function in real time. Placenta 2014; 35(5): 303-304.

3. Hoffman, M. C., Rumer, K. K., Kramer, A., Lynch, A. M., \& Winn, V. D. Maternal and fetal alternative complement pathway activation in early severe preeclampsia. Am J Reprod Immunol. 2013; 71(1): 5560.

4. Duhig, K., Vandermolen, B., \& Shennan, A. Recent advances in the diagnosis and management of pre-eclampsia. F1000Res. 2018;7:242.

5. Savaj, S., \& Vaziri, N. D. An Overview of Recent Advances in Pathogenesis and Diagnosis of Preeclampsia. Iran J Kidney Dis. 2012; 6(5):334-8.

6. Weissgerber, T. L., \& Mudd, L. M. Preeclampsia and diabetes. Curr Diab Rep. 2015;15(3):579-585.

7. Martin, J. N., Blake, P. G., Perry, K. G., Mccaul, J. F., Hess, L. W., \& Martin, R. W. The natural history of HELLP syndrome: Patterns of disease progression and regression. Am J Obstet Gynecol. ogy. 1991; 164(6): 1500-1513

8. Cakmak, B., Toprak, M., Nacar, M. C., \& Karatas, A. Late Postpartum HELLP Syndrome 60 Hours after Delivery Associated with Mild Pre-eclampsia. J Clin Diagn Res. 2013; 7(12): 2998-9.

9. Jebbink, J., Wolters, A., Fernando, F., Afink, G., Post, J. V., \& Ris-Stalpers, C. Molecular genetics of preeclampsia and HELLP syndrome - A review. Biochimica et Biophysica Acta. 2012;1822(12): 1960-1969.

10. Burton, G. J., Fowden, A. L., \& Thornburg, K. L. Placental Origins of Chronic Disease. Physiol Rev. 2016; 96(4): 1509-65.

11. Soares, M. J., Iqbal, K., \& Kozai, K. Hypoxia and Placental Development. Birth Defects Res.. 2017;109(17): 1309-1329.

12. Amaral, L. M., Wallace, K., Owens, M., \& LaMarca, B. Pathophysiology and Current Clinical Management of Preeclampsia. Curr Hypertens Rep. 2017; 19(8): 61.

13. Pinheiro, M. B., Carvalho, M. G., Martins-Filho, O. A., Freitas, L. G., 
Godoi, L. C., Alpoim, P. N., Dusse, L. M. Severe preeclampsia: Are hemostatic and inflammatory parameters associated? Clin Chim Acta. 2014; 427:65-70.

14. Uzan, J., Carbonnel, M., Piconne, O., Asmar, R., \& Ayoubi, J. M. Preeclampsia: pathophysiology, diagnosis, and management. Vasc Health Risk Manag. 2011; 7: 467-74.

15. Hladunewich, M., Karumanchi, S. A., \& Lafayette, R. Pathophysiology of the Clinical Manifestations of Preeclampsia. Clin J Am Soc Nephrol. 2007; 2(3): 543-549.

16. Cornette, J., Herzog, E., Buijs, E., Duvekot, J., Rizopoulos, D., Hop, W., Tibboel D,Steegers, E. Microcirculation in women with severe pre-eclampsia and HELLP syndrome: A case-control study. BJOG. $2014 ; 121(3): 363-70$.

17. Jeyabalan A. Epidemiology of preeclampsia: impact of obesity. Nutr Rev. 2013; 71 Suppl 1(0 1): S18-25.

18. Chaiworapongsa, T., Chaemsaithong, P., Korzeniewski, S. J., Yeo, L., \& Romero, R. Pre-eclampsia part 2: prediction, prevention and management. Nat Rev Nephrol. 2014; 10(9): 531-40.

19. Chaiworapongsa, T., Chaemsaithong, P., Yeo, L., \& Romero, R. Preeclampsia part 1: current understanding of its pathophysiology. Nat Rev Nephrol.2014; 10(8): 466-80.

20. Steegers, E. A., Dadelszen, P. V., Duvekot, J. J., \& Pijnenborg, R. Preeclampsia. Lancet. 2010; 376(9741): 631-644.

21. Goel, A., Jamwal, K. D., Ramachandran, A., Balasubramanian, K. A., \& Eapen, C. E. Pregnancy-Related Liver Disorders. J Clin Exp Hepatol. 2014; 4(2); 151-162.

22. Hagmann, H., Thadhani, R., Benzing, T., Karumanchi, S. A., \& Stepan, $\mathrm{H}$. The Promise of Angiogenic Markers for the Early Diagnosis and Prediction of Preeclampsia. Clin Chem. 2012; 58(5): 837-845.

23. Hund, M., Verhagen-Kamerbeek, W., Reim, M., Messinger, D., Does, R. V., \& Stepan, H. Influence of the sFlt-1/PIGF ratio on clinical decision-making in women with suspected preeclampsia - the PreOS study protocol. Hypertens Pregnancy. 2015; 34(1): 102-115.

24. Redman, C. W., \& Staff, A. C. Preeclampsia, biomarkers, syncytiotrophoblast stress, and placental capacity. Am J Obstet Gynecol. 2015;213(4 Suppl):S9.e1, S9-11

25. Metz, T. D., Allshouse, A. A., Euser, A. G., \& Heyborne, K. D. Preeclampsia in high risk women is characterized by risk groupspecific abnormalities in serum biomarkers. Am J Obstet Gynecol. 2014 Nov; 211(5): 512.e1-512.e6

26. Amorim, M. M., Katz, L., Barros, A. S., Almeida, T. S., Souza, A. S., \& Faúndes, A. Maternal outcomes according to mode of delivery in women with severe preeclampsia: A cohort study. J Matern Fetal Neonatal Med. 2015 ;28(6):654-60.

27. Kinay, T., Kucuk, C., Kayikcioglu, F., \& Karakaya, J. Severe Preeclampsia versus HELLP Syndrome: Maternal and Perinatal Outcomes at $<34$ and $\geq 34$ Weeks' Gestation. Balkan Med J. 2015; 32(4): 359-363.

28. Herzog, E. M., Eggink, A. J., Reijnierse, A., Kerkhof, M. A., Krijger, R. R., Roks, A. J., Steegers-Theunissen, R. P. Impact of early- and lateonset preeclampsia on features of placental and newborn vascular health. Placenta. 2017;49: 72-79.

29. Carter, E. B., Conner, S. N., Cahill, A. G., Rampersad, R., Macones, G. A., \& Tuuli, M. G. Impact of fetal growth on pregnancy outcomes in women with severe preeclampsia. Pregnancy Hypertens. 2017; 8: $21-25$.

30. Dacaj, R., Izetbegovic, S., Stojkanovic, G., \& Dreshaj, S. Elevated Liver Enzymes in Cases of Preeclampsia and Intrauterine Growth Restriction. Med Arc. 2016; 70(1): 44-7

31. Bokslag, A., Weissenbruch, M.V., Mol, B.W., \& Groot, C. J. Preeclampsia; short and long-term consequences for mother and neonate.
Early Hum Dev. 2016; 102: 47-50.

32. Berry, E. L., \& Iqbal, S. N. HELLP Syndrome at 17 Weeks Gestation: A Rare and Catastrophic Phenomenon. J Clin Gynecol Obstet. 2014; 3(4): 147-150.

33. Haram, K., Mortensen, J. H., \& Nagy, B. Genetic Aspects of Preeclampsia and the HELLP Syndrome. J Pregnancy.2014: 1-13.

34. Rao, D., Chaudhari, N. K., Moore, R. M., \& Jim, BHELLP syndrome: a diagnostic conundrum with severe complications. BMJ Case Rep. 2016: bcr2016216802.

35. Haram, K., Svendsen, E., \& Abildgaard, U. The HELLP syndrome: Clinical issues and management. A Review. BMC Pregnancy Childbirth, 2009:9(1).

36. Weiner, E., Schreiber, L., Grinstein, E., Feldstein, O., Rymer-Haskel, N., Bar, J., \& Kovo, M. The placental component and obstetric outcome in severe preeclampsia with and without HELLP syndrome. Placenta. 2016; 47: 99-104.

37. Turgut, A., Demirci, O., Demirci, E., \& Uludoğan, M. Comparison of maternal and neonatal outcomes in women with HELLP syndrome and women with severe preeclampsia without HELLP syndrome. J Prenat Med. 2010; 4(3): 51-8.

38. Mihu D, Costin N, Mihu CM, Seicean A, Ciortea R. "HELLP Syndrome - a Multisystemic Disorder." J Gastrointestin Liver Dis. 2007;16(4):419-24

39. Abildgaard, U., \& Heimdal, K. Pathogenesis of the syndrome of hemolysis, elevated liver enzymes, and low platelet count (HELLP): A review. Eur J Obstet Gynecol Reprod Biol. 2013; 166(2): 117-123.

40. Yang, L., Ren, C., Mao, M., \& Cui, S. Prognostic Factors of the Efficacy of High-dose Corticosteroid Therapy in Hemolysis, Elevated Liver Enzymes, and Low Platelet Count Syndrome During Pregnancy. Medicine (Baltimore). 2016 Mar;95(13):e3203. doi: 10.1097/ MD.0000000000003203

41. Mao, M., \& Chen, C. Corticosteroid Therapy for Management of Hemolysis, Elevated Liver Enzymes, and Low Platelet Count (HELLP) Syndrome: A Meta-Analysis. Med Sci Monit. 2015; 21: 3777-3783.

42. Martin, J. N., Thigpen, B. D., Rose, C. H., Cushman, J., Moore, A., \& May, W. L. Maternal benefit of high-dose intravenous corticosteroid therapy for HELLP syndrome. Am J Obstet Gynecol. 2003;189(3): 830-834.

43. Lam, M. C., \& Dierking, E. Intensive Care Unit issues in eclampsia and HELLP syndrome. Int J Crit IIIn Inj Sci.. 2017; 7(3): 136. doi:10.4103/ijciis.ijciis_33_17

44. Thilaganathan, B. Placental syndromes: Getting to the heart of the matter. Ultrasound Obstet Gynecol. 2017; 49(1): 7-9.

45. Manokhina, I., Wilson, S. L., \& Robinson, W. P. Noninvasive nucleic acid-based approaches to monitor placental health and predict pregnancy-related complications. Am J Obstet Gynecol. 2015; 213(4 Suppl):S197-206.

46. Albu, AR, Anca, AF, Horhoianu,VV and Horhoianu, IA. Predictive factors for intrauterine growth restriction. J Med Life. 2014; 7(2): 165-171.

47. Benton, S. J., Mccowan, L. M., Heazell, A. E., Grynspan, D., Hutcheon, J. A., Senger, C., Dadelszen, P. V. Placental growth factor as a marker of fetal growth restriction caused by placental dysfunction. Placenta. 2016; 42: 1-8.

48. Mandò C, De Palma C, Stampalija T, Anelli GM, Figus M, Novielli C, Parisi F, Clementi E, Ferrazzi E, Cetin I. Placental mitochondrial content and function in intrauterine growth restriction and preeclampsia. Am J Physiol Endocrinol Metab. 2014 Feb 15;306(4):E404-13. 